\title{
Ectopic Tooth in the Anterior Wall of Maxillary Sinus
}

\author{
${ }^{1}$ Sanidhya Surana, ${ }^{2}$ Deepak Thakur, ${ }^{3}$ Sheetal Kapse, ${ }^{4}$ Mukesh K Kashyap
}

\section{ABSTRACT}

A 16-year-old male patient reported to our department with a chief complaint of pain and swelling in the upper left cheek region. On examination, a maxillary canine was found ectopically in the anterior wall of maxillary sinus. Ectopic eruption of teeth into regions other than the oral cavity is rare. We present one such case of ectopic eruption of maxillary canine.

Keywords: Ectopic tooth, Impacted canine, Maxillary sinus.

How to cite this article: Surana S, Thakur D, Kapse S, Kashyap MK. Ectopic Tooth in the Anterior Wall of Maxillary Sinus. Int J Recent Surg Med Sci 2017;3(2):111-113.

Source of support: Nil

Conflict of interest: None

\section{INTRODUCTION}

According the literature available until date, the maxillary canines seem to be the second most commonly impacted permanent teeth. ${ }^{1}$ Distance traveled by the developing canine to reach the occlusion, discrepancy in the length of the maxillary arch, alveolar bone condensation, root dilaceration, or any form of ankylosis are the various theories suggested. ${ }^{1}$ The crown of impacted canine can be located labially or palatally, but, at rare occasions, the tooth may be found in ectopic locations, such as nasal septum, condyle, coronoid process, palate, or maxillary sinus. ${ }^{2}$ Presence of teeth in the maxillary sinus is a rare finding, and the condition may be undiagnosed for years and found accidentally on radiographic examination. The tooth may be displaced into sinus due to trauma (resulting in displacement of tooth bud), infection, crowding, or genetic factors.

We present a case of ectopic tooth in the maxillary sinus with its implications and management.

${ }^{1}$ Fellow, ${ }^{2}$ Reader, ${ }^{3}$ Senior Lecturer, ${ }^{4}$ Postgraduate Student

${ }^{1}$ Department of Oral and Maxillofacial Surgery, Sharad Pawar Dental College \& Hospital, Wardha, Maharashtra, India

${ }^{2,4}$ Department of Oral and Maxillofacial Surgery, Rungta College of Dental Sciences \& Research, Bhilai, Chhattisgarh, India

${ }^{3}$ Department of Oral and Maxillofacial Surgery, Mamata Dental College, Khammam, Telangana, India

Corresponding Author: Sanidhya Surana, Fellow, Department of Oral and Maxillofacial Surgery, Sharad Pawar Dental College \& Hospital, Wardha, Maharashtra, India, Phone: +918889913272, e-mail: drsssos97@gmail.com

\section{CASE REPORT}

A 16-year-old male patient reported to the Department of Oral and Maxillofacial Surgery with a chief complaint of pain and swelling in the upper left cheek region since 20 days (Fig. 1A). The patient gave a history of trauma 12 years back with recurrent pain and swelling, which was relieved on taking antibiotics.

On examination, retained deciduous left maxillary canine was found, while the contralateral permanent canine was present. A carious left maxillary lateral incisor and missing maxillary canine were evident (Figs 1B and C). On radiographic examination, periapical cyst in relation to lateral incisor was seen, and upper left maxillary canine was found within the maxillary sinus. The impacted tooth was inverted, with the crown directing toward the infraorbital rim and was embedded in the anterior wall (Figs 2 and 3).

Under general anesthesia, the periapical cyst was enucleated with apicoectomy of lateral incisor. CaldwellLuc procedure was performed to remove the impacted tooth. The postoperative phase was uneventful without any complications. The patient is being followed up.

\section{DISCUSSION}

Tooth development results from a complicated multistep interaction between the oral epithelium and underlying mesenchymal tissue. Abnormal tissue interaction during development may potentially result in ectopic tooth development and eruption. Ectopic eruption may result owing to one of these three processes: Developmental disturbance, iatrogenic activity, or pathologic process, such as a tumor or a cyst. ${ }^{3}$ Ectopic eruption of teeth into regions other than the oral cavity is rare, although there have been reports of teeth in the nasal cavity, mandibular condyle, coronoid process, palate, and maxillary sinus. ${ }^{3}$

The etiology of ectopic eruption has not yet been completely clarified, but many theories have been suggested, including trauma, infection, developmental anomalies, and pathologic conditions, such as dentigerous cysts. ${ }^{3}$ It is believed that the displacement of teeth buds by the expansion of these dental cysts results in the "ectopic" eruption of such teeth. ${ }^{3}$ There have been reports adding to a growing number of cases in which the maxillary sinus is involved by calcified structures, such as ectopic tooth, supernumerary tooth, osteomas, and free bone. In the present case, the ectopic tooth was left maxillary 


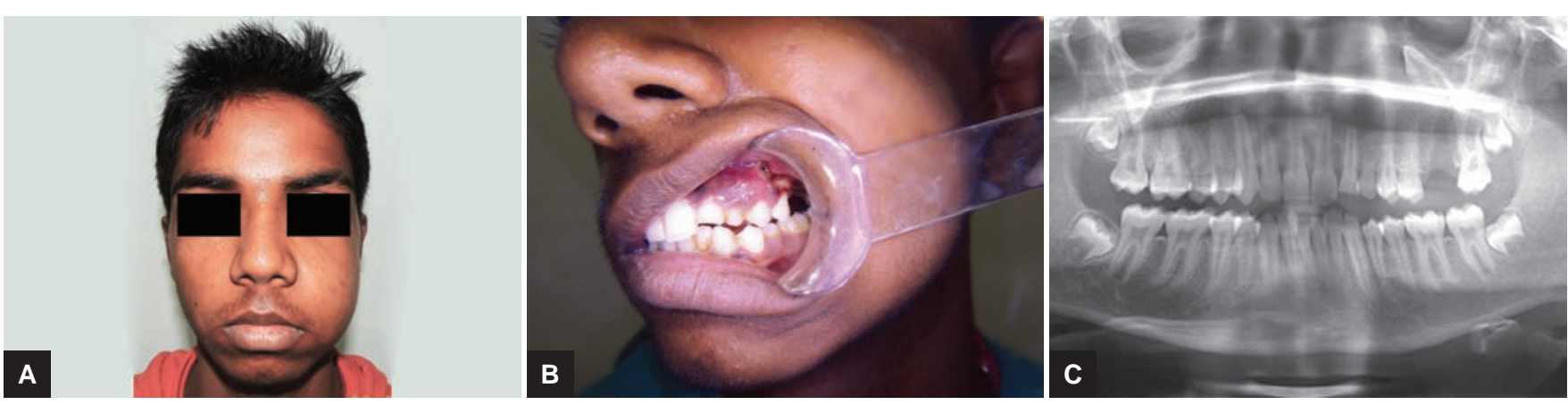

Figs 1A to C: (A) Frontal view; (B) occlusion on left side; and (C) orthopantomogram

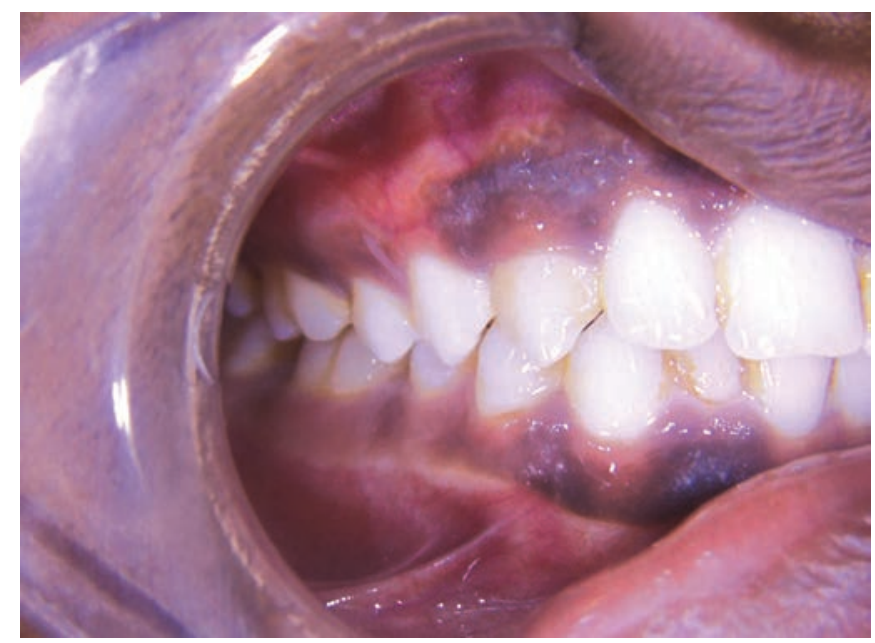

Fig. 2: Occlusion on the left side

canine. ${ }^{4}$ Although ectopic, impacted teeth found in the maxillary sinus are usually normal in shape; a few cases involving malformed teeth have been reported. ${ }^{4}$ In such cases, dentigerous cysts in the maxillary sinus may be discovered on radiographic examination. Foreign bodies, metallic or nonmetallic, may also lay dormant in the maxillary sinus. In other instances, patients become symptomatic and experience the classic signs of sinus disease. These may include swelling, facial pain, headache, and nasolacrimal obstruction. A large maxillary cyst involves the whole sinus and can transmit pressure to the walls of sinus; consequently, ophthalmologic and nasal symptoms may develop. ${ }^{3}$ Altas et $\mathrm{al}^{5}$ reported epiphora that occurred because of pressure to the nasolacrimal canal of a dentigerous cyst associated with an ectopic canine in the maxillary sinus. Avitia et $\mathrm{al}^{6}$ reported a case of orbital proptosis resulting from a dentigerous cyst in the maxillary sinus associated with a displaced tooth. Among the 17 case reports summarized by Buyukkurt et al, ${ }^{3}$ only four patients had no clinical symptoms. Many surgical approaches have been reported in the literature including the endoscopic removal of such ectopic teeth and associated lesions. Although the traditional Caldwell-Luc procedure provides a direct view into the maxillary sinus, it is associated with more morbidity than

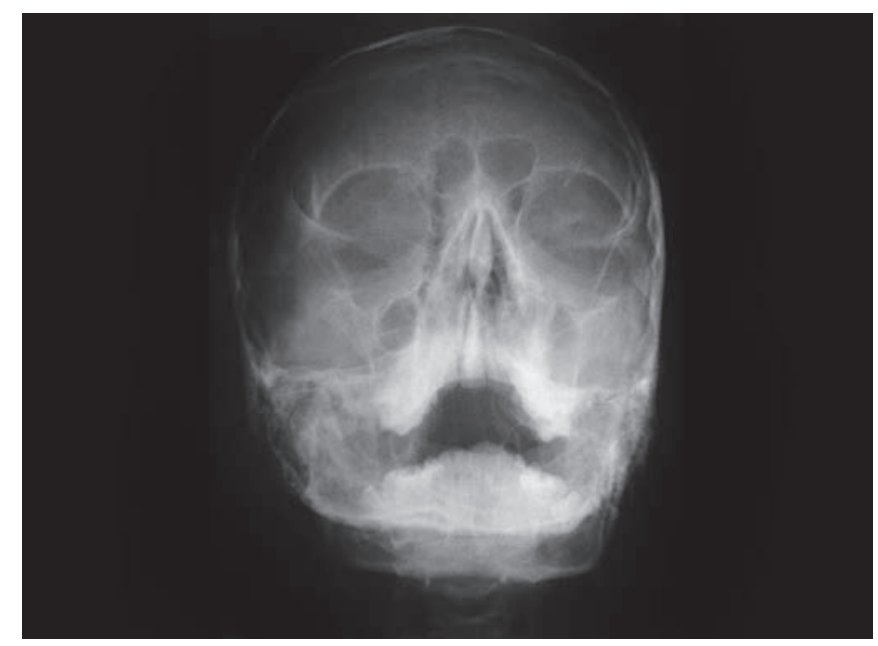

Fig. 3: Paranasal sinus view

transnasal endoscopy. Transnasal extradition of the tooth may be attempted if the tooth is small and sited near the maxillary ostium. Di Pasquale and Shermetaro ${ }^{7}$ used a nasal endoscope to create a middle meatal antrostomy and deliver the ectopic tooth and its cystic contents. The endoscopic techniques are being used for removal of intranasal ectopic tooth obstructing nasal cavity and ectopic maxillary third molar obstructing osteomeatal complex. ${ }^{7}$ Hasbini et $\mathrm{l}^{8}$ reported that the surgeon should consider an endoscopic sinus approach rather than more traumatic techniques, such as the Caldwell-Luc method. Postoperative follow-up with radiographic examination at regular intervals is mandatory to rule out any recurrence.

\section{CONCLUSION}

Variations will never cease to exist, and, hence, documentation of the slightest change is mandatory. Until date, what has been seen and reviewed is an association of dentigerous cyst along with impacted teeth in the sinus. In our case, there was no cystic change within the sinus seen other than the opacification in the anterior wall. A conventional Caldwell-Luc operation was performed, and the tooth's crown and root were removed separately. 


\section{REFERENCES}

1. Araújo EA, Araújo CV, Tanaka OM. Apicotomy: surgical management of maxillary dilacerated or ankylosed canines. Am J Orthod Dentofacial Orthop 2013 Dec;144(6):909-915.

2. Gadre KS, Waknis P. Intra-oral removal of ectopic third molar in the mandibular condyle. Int J Oral Maxillofac Surg 2010 Mar;39(3):294-296.

3. Buyukkurt MC, Omezli MM, Miloglu O. Dentigerous cyst associated with an ectopic tooth in the maxillary sinus: a report of 3 cases and review of the literature. Oral Surg Oral Med Oral Pathol Oral Radiol Endod 2010 Jan;109(1):67-71.

4. Kamei T, Inui M, Nakamura S, Tagawa T. Bony ossicle in the maxillary sinus containing a tooth. J Oral Maxillofac Surg 2001 Sep;59(9):1108-1111.
5. Altas E, Karasen RM, Yilmaz AB, Aktan B, Kocer I, Erman Z. A case of a large dentigerous cyst containing a canine tooth in the maxillary antrum leading to epiphora. J Laryngol Otol 1997 Jul;111(7):641-643.

6. Avitia S, Hamilton JS, Osborne RF. Dentigerous cyst presenting as orbital proptosis. Ear Nose Throat J 2007 Jan;86(1): 23-24.

7. Di Pasquale P, Shermetaro C. Endoscopic removal of a dentigerous cyst producing unilateral maxillary sinus opacification on computed tomography. Ear Nose Throat J 2006 Nov;85(11):747-748.

8. Hasbini AS, Hadi U, Ghafari J. Endoscopic removal of an ectopic third molar obstructing the osteomeatal complex. Ear Nose Throat J 2001 Sep;80(9):667-670. 